\title{
Vitamin C, Chlorophyll Content and Total Phenolic Compounds in Artemisia lactiflora as Affected by Different Organic Fertilizers
}

\author{
Narin Taokaenchan $^{1 *}$, Pawinee Areesrisom ${ }^{1}$, and Sakchai Satienperakul ${ }^{2}$ \\ ${ }^{1}$ Department of Medicinal Plant Science, Faculty of Agricultural Production, \\ Maejo University, Chiang Mai 50290, Thailand \\ ${ }^{2}$ Department of Chemistry, Faculty of Science, Maejo University, Chiang Mai \\ 50290, Thailand \\ *Corresponding author.E-mail: narin_t15@hotmail.com \\ https://doi.org/10.12982/CMUJNS.2020.0064
}

Received: February 24, 2020

Revised: April 19, 2020

Accepted: April 22, 2020

\begin{abstract}
The objectives of this current study were to determine the varying contents of vitamin C, chlorophyll, total phenolic compounds in White mugwort (Artemisia lactiflora) which were tested under different types of organic fertilizer. Completely randomized design with four treatments (applications of no fertilizer, cow, chicken and bat manures) was assigned for the field experiments at Department of Medicinal Plant Science, Faculty of Agricultural Production, Maejo University in Chiang Mai, Thailand. The results showed that the sampled plants with chicken manure application yielded the highest fresh $(31.00 \pm 1.00 \mathrm{~g}$ FW/plant) and dried weights $(3.20 \pm 0.20 \mathrm{~g} \mathrm{DW/plant)}$. Furthermore, plants with chicken manure treatment also gave the highest chlorophyll content of $0.93 \mathrm{mg} / \mathrm{g} \mathrm{FW}$. Whereas, the highest levels of vitamin $C$ $(1.35 \mathrm{mg} / 100 \mathrm{~g} \mathrm{FW})$ and total phenolic compounds $(4.84 \mathrm{mgGAE} / \mathrm{g} D W)$ were found in plants with cow manure treatment.
\end{abstract}

Keywords: Artemisia Lactiflora, Organic fertilizer, Total phenolic compounds, Vitamin C

\section{INTRODUCTION}

Thai herbs have been used in traditional medicine in Thailand for many centuries. They are widely known for being dietary supplements and important sources of antioxidants (Hafizah et al., 2010; Hunaefi and Smetanska, 2013; Almatar et al., 2014). Health benefits of Thai herbs have been reported for 
analgesics, anti-microbials, anti-inflammatories, immunostimulants, antidiarrheal, digestive aids, fertility regulators, malarial discharged (Saokaew et al., 2011) and so on. Artermisia lactiflora is one of medicinal plants in Asteraceae family. It is commonly called 'White mugwort' (Figure S1) or 'Jinjuchai'(Thailand name) is frequently used not only as a vegetable or spice but also has been used as a herb for both the Chinese and Thai traditional medicine. For example, the leaves, flowers and stems were reported that it is able to treat menstrual and liver disorders (Kulprachakarn et al., 2019). The plants are an important source of natural active products such as vitamin, chlorophyll and phenolic acids (Lesing, 2015). These products are responsible for antioxidant activities in biological properties.

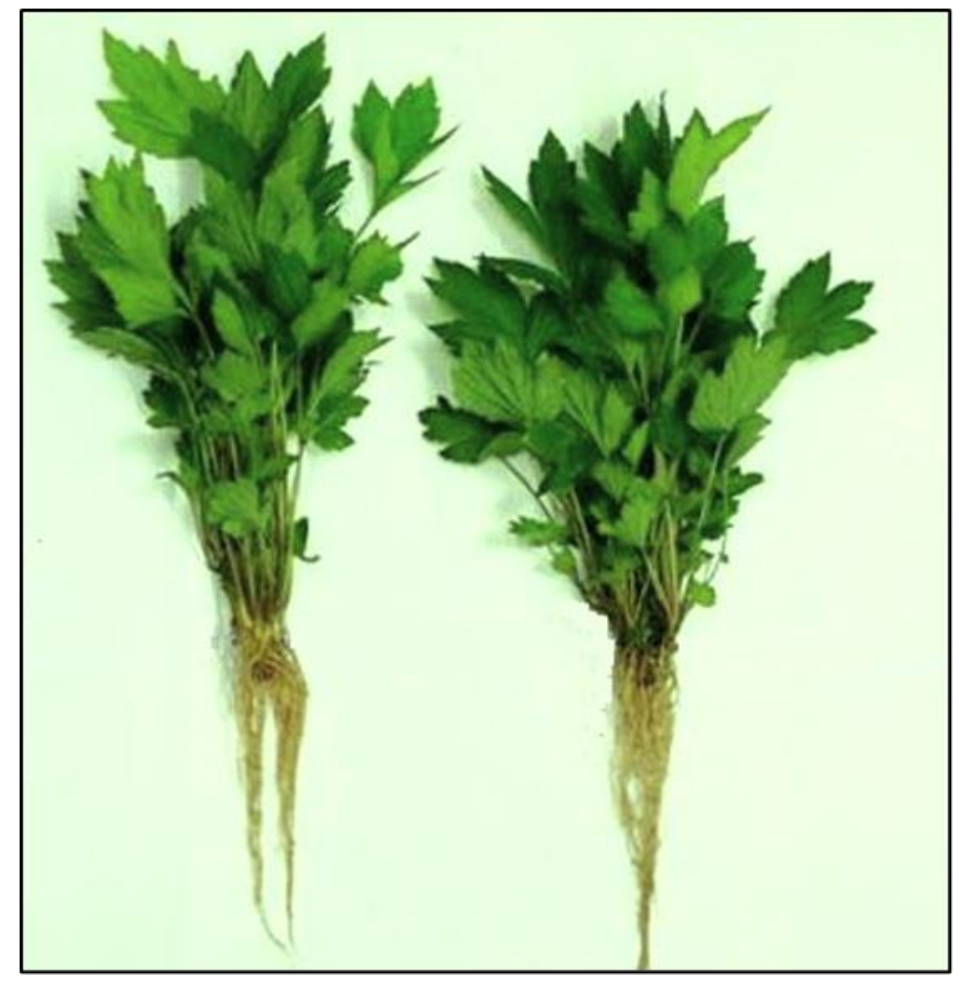

Figure S1. Artermisia lactiflora.

Recently, maximizing economical crop yield is a main goal on agricultural production. Thus, many synthetic chemical fertilizers have been widely and heavily applied in conventional farming system, but the using of inorganic or chemical fertilizer led to chemical and pesticides residue in plants and environmental (Roussos et al., 2019). In addition, it is reducing the antioxidant levels in plant (Rossetto et al., 2013). Regarding the above, many researches have recommended that the uses of organic manures or organic fertilizer, because the advantages of organic fertilizer application have been studied and confirmed the beneficial effects on quality of crops, enhancing antioxidant constituent in plants (Fallah et al., 2018). Furthermore, the physical and biological soil properties are 
improved when applying organic fertilizers (Islam et al., 2017; Roussos et al., 2017).

Many plant scientists have been investigating the effects of different organic fertilizers on many types of plant herbs, including types and amounts of primary and secondary metabolites (Siddiqui et al., 2011; Pandey et al., 2015). Up to date, no study about the response of secondary metabolites and antioxidant activities under different fertilizers in Artermisia lactiflora have been reported yet. In addition, as described in the preceding paragraphs, it is suggested that, the development and phytochemicals of the crops system might be satisfied with the use of organic manures, thus reducing in an employment of synthetic fertilize. Therefore, the objectives of this study were to examine the effects of different types of organic fertilizers (cow, chicken and bat manure) on the production of the total phenolics, vitamin $\mathrm{C}$ and chlorophyll in White mugwort.

\section{MATERIALS AND METHODS}

\section{Materials}

L-Ascorbic acid, gallic acid, Folin-Ciocalteu phenol reagent and metaphosphoric acid were purchased from the Merck Co. (Germany). Acetone and methanol were purchased from the RCI Labscan CO., Ltd. (Ireland). Sodium carbonate was obtained from the QRec Co., Ltd. (New Zealand). All other chemicals were reagent grade.

\section{Plant materials}

Artemisia lactiflora was obtained from Chiang Mai Royal Agricultural Research Center, Chiang Mai, Thailand. In order to propagate this plant, its shoot tip was cut in 10-15 cm long, planted in the pots containing a 1:1 mixture of soil and husk and subsequently cultivated in a greenhouse under the natural light condition for 30 days.

\section{The experimental design}

Field experiments were conducted at the demonstration farm in Maejo University, Chiang Mai (383 $\mathrm{m}$ above MSL, $18^{\circ} 55^{\prime} 05^{\prime} ' \mathrm{~N}$ and $90^{\circ} 03^{\prime} 06^{\prime} \mathrm{E}$ ) during September to November, 2015. The average temperature of Chiang Mai is about $27.1^{\circ} \mathrm{C}$ with the annual rainfall of $1,050.0 \mathrm{~mm}$. Completely randomized design (CRD) with three replications was used for this experiment. The plant materials were planted in 10-inch pots containing a 1:1 mixture of soil: husk. Four types of organic fertilizer with different application rates were set as a treatment e.g. $10 \mathrm{t} / \mathrm{ha}$ of cow manure, $5 \mathrm{t} / \mathrm{ha}$ of chicken and $5 \mathrm{t} / \mathrm{ha}$ of bat manure and control (no fertilizer added). Treatments were given to the plants at 7 days after planting. These plants were watered every other day until harvesting at 60 days after planting. The freshly harvested aerial parts were immediately weighed for the 
fresh weight determination and were dried at $45^{\circ} \mathrm{C}$ for 72 hours in a drying oven for dry weight determination.

Nutrient compositions of all organic manure were analysed by followed the Testing methods for fertilizers (2016), which nitrogen, phosphorus and potassium elements were measured with micro-kjedahl method, spectrophotometry and atomic absorption spectrophotometry, respectively. The nutrients of these manure are presented in Table 1.

Table 1. The Nutrient composition in organic fertilizer.

\begin{tabular}{lccc}
\hline $\begin{array}{c}\text { Organic } \\
\text { fertilizers }\end{array}$ & $\mathbf{N}(\boldsymbol{\%})$ & $\mathbf{P}(\boldsymbol{\%})$ & $\mathbf{K}(\boldsymbol{\%})$ \\
\hline Cow manure & 1.11 & 0.52 & 0.43 \\
Chicken manure & 3.11 & 1.79 & 1.87 \\
Bat manure & 2.02 & 2.34 & 0.42 \\
\hline
\end{tabular}

\section{Vitamin C determination}

The method of Park et al. (2014) was modified and used to measure the concentrations of vitamin $\mathrm{C}$. Three gram of fresh leaves were ground by using a pestle and mortar and added $25 \mathrm{~mL}$ of $3 \% \mathrm{v} / \mathrm{v}$ of metaphosphoric solution. The homogenate was then filtered and transferred to a $50 \mathrm{~mL}$ volumetric flask. Then adjusting the final volume of $50 \mathrm{~mL}$ with $3 \% \mathrm{v} / \mathrm{v}$ of metaphosphoric solution. The extract solution was passed through a $0.45 \mu \mathrm{m}$ nylon filter.

HPLC method including an external calibration was used to quantified the concentration of vitamin C in term of $\mathrm{mg} / 100 \mathrm{~g}$ of fresh plant. RP-HPLC analysis was performed with the Agilent 1100 series HPLC system (Agilent; USA), HPLC parameters were described in Table 2.

Table 2. Chromatographic parameters for Vitamin C determination by HPLC method.

\begin{tabular}{lc}
\hline \multicolumn{1}{c}{ Parameters } & Condition value \\
\hline Mobile phase & $0.2 \mathrm{M} \mathrm{KH}_{2} \mathrm{PO}_{4} \mathrm{pH} 2.4$ \\
Flow rate & $0.8 \mathrm{~mL} / \mathrm{min}$ \\
Injection volume & $20 \mu \mathrm{L}$ \\
Column & $\mathrm{C}-18$ Hypersil-ODS $(4.0 \times 250 \mathrm{~mm}, 5 \mu \mathrm{m})$ \\
Column temperature & $25{ }^{\circ} \mathrm{C}$ \\
UV-VIS detector wavelength & $254 \mathrm{~nm}$ \\
\hline
\end{tabular}




\section{Estimation of chlorophyll content}

Determination of chlorophyll content was followed the method of Kamble et al., (2015). Briefly, $1 \mathrm{~g}$ of fresh leaves were cut into small pieces and ground in $20 \mathrm{~mL}$ of $80 \%$ acetone and $0.5 \mathrm{~g}$ of $\left(\mathrm{MgCO}_{3}\right)$ powder. Subsequently, the extract was centrifuged at 5,000 rpm for 5 mins and the supernatant was transferred to a $100 \mathrm{~mL}$ volumetric flask and the volume was made up to $100 \mathrm{~mL}$ with the addition of $80 \%$ acetone. The absorbance of the solution is measured by using a spectrophotometer (Genesys 10S, Thermo Scientific, USA) at $645 \mathrm{~nm}$ and 663 $\mathrm{nm}$ along with $80 \%$ acetone as a blank. The concentration of chlorophyll content was calculated as the following equation:

$$
\text { Chlorophyll content }=20.2(\mathrm{~A} 645)+8.02(\mathrm{~A} 663)
$$

where A645 and A663 are the absorbance values of the sample solution at 645 and $663 \mathrm{~nm}$, respectively.

\section{Total phenolic compounds determination}

The extraction and quantification methods were performed as previously described in Pumtes et al., (2012) and Namjooyan et al., (2010), respectively. The fresh leaves of the plants were dried in an oven (UM 400, Memmert, Germany) at the temperature of $45^{\circ} \mathrm{C}$ until dry and then ground to the fine powders. Three gram of ground sample were extracted in $30 \mathrm{~mL}$ methanol and heated at $40{ }^{\circ} \mathrm{C}$ for 3 hours in the water bath. The extracted aqueous phase was subsequently filtered by using Whatman No.1, then evaporated and dissolved the pellet in $5 \mathrm{ml}$ methanol. Total phenolic compounds were measured by using the FolinCiocalteu assay. An aliquot of $0.1 \mathrm{~mL}$ extracts was put into a flask containing $2 \mathrm{~mL}$ of $2 \% \mathrm{w} / \mathrm{v}$ sodium carbonate followed by adding $0.1 \mathrm{~mL}$ Folin Ciocalteu's phenol reagent. The mixture solution was thoroughly mixed and stood for $30 \mathrm{mins}$ at ambient temperature. After that, the solution was measured the absorbance by using a spectrophotometer (Genesys 10S, Thermo Scientific, USA) at $750 \mathrm{~nm}$. Total phenolic compounds was expressed as mg gallic acid equivalents (GAE) per gram of dry weight.

\section{Statistical analysis}

All experiments were conducted in three replications. Data from all three replications was used to calculate mean value and the results were expressed in mean + SD. Analysis of variance using one-way ANOVA at a significance level of 0.05 and Duncan's New Multiple Range Test were analysed on all response variables. 


\section{RESULTS}

\section{Yield of Artemisia lactiflora}

The highest yield of Artemisia lactiflora was obtained from the chicken manure application. Fresh and dry weight of plants were $31.00 \pm 1.00 \mathrm{~g} \mathrm{FW} /$ plant and 3.20 $\pm 0.20 \mathrm{~g} \mathrm{DW} /$ plant (Table 3), respectively whereas lowest yield per unit area $(14.17 \pm 0.29 \mathrm{~g} \mathrm{FW/plant)}$ was found in the control treatment. The result indicated that yield was higher when using chicken manure compared with the other treatments.

Table 3. The fresh and dry weight of Artemisia lactiflora at different organic fertilizer.

\begin{tabular}{lcc}
\hline Organic fertilizers & Fresh weight $(\mathbf{g}$ FW/plant $)$ & Dry weight $(\mathrm{g} \mathrm{DW} /$ plant $)$ \\
\hline Control & $14.17 \pm 0.29^{\mathrm{d}}$ & $1.68 \pm 0.03^{\mathrm{c}}$ \\
Cow manure & $15.33 \pm 0.50^{\mathrm{c}}$ & $1.84 \pm 0.02^{\mathrm{c}}$ \\
Chicken manure & $31.00 \pm 1.00^{\mathrm{a}}$ & $3.20 \pm 0.20^{\mathrm{a}}$ \\
Bat manure & $18.47 \pm 0.53^{\mathrm{b}}$ & $2.10 \pm 0.10^{\mathrm{b}}$ \\
\hline
\end{tabular}

Note: Different letters within a column indicate significant differences at $P<0.05$.

\section{Effect of organic fertilizers on vitamin C in Artemisia Lactiflora}

The chromatogram of extract Artemisia lactiflora solution was presented in Figure 1. The retention time of vitamin $\mathrm{C}$ was $5.7 \mathrm{~min}$. The levels of vitamin $\mathrm{C}$ ranged between 0.93 to $1.35 \mathrm{mg} / 100 \mathrm{~g} \mathrm{FW}$ (Table 4). However, there was statistically significant effect of organic fertilizers on concentrations of vitamin $\mathrm{C}(P<0.05)$. It was noticed that the highest level of vitamin $\mathrm{C}(1.35 \pm 0.02 \mathrm{mg} /$ $100 \mathrm{~g} \mathrm{FW}$ ) in Artemisia lactiflora was obtained from a treatment of cow manure application. On the other hand, the smaller vitamin $\mathrm{C}$ was observed in the Artemisia lactiflora fresh leafs was obtained in the chicken manure application with the value of $0.93 \mathrm{mg} / 100 \mathrm{~g} \mathrm{FW}$.

\section{The chlorophyll content in Artemisia Lactiflora in the different organic fertilizers}

The fresh leaf of white mugwort were analysed on the chlorophyll content. The study has revealed that the chlorophyll content ranges from 0.24 to $0.93 \mathrm{mg} / \mathrm{g} \mathrm{FW}$ (Table 4). The results of this study also showed significant differences $(P<0.05)$ for the chlorophyll content due to the effect of different organic manures. From the result it is also seen that application of chicken manure presented the highest content of total chlorophyll in this research. The highest chlorophyll content was $0.93 \mathrm{mg} / \mathrm{g}$ FW. The smallest of chlorophyll content was obtained with control treatment with the value of $0.24 \mathrm{mg} / \mathrm{g} \mathrm{FW}$. 


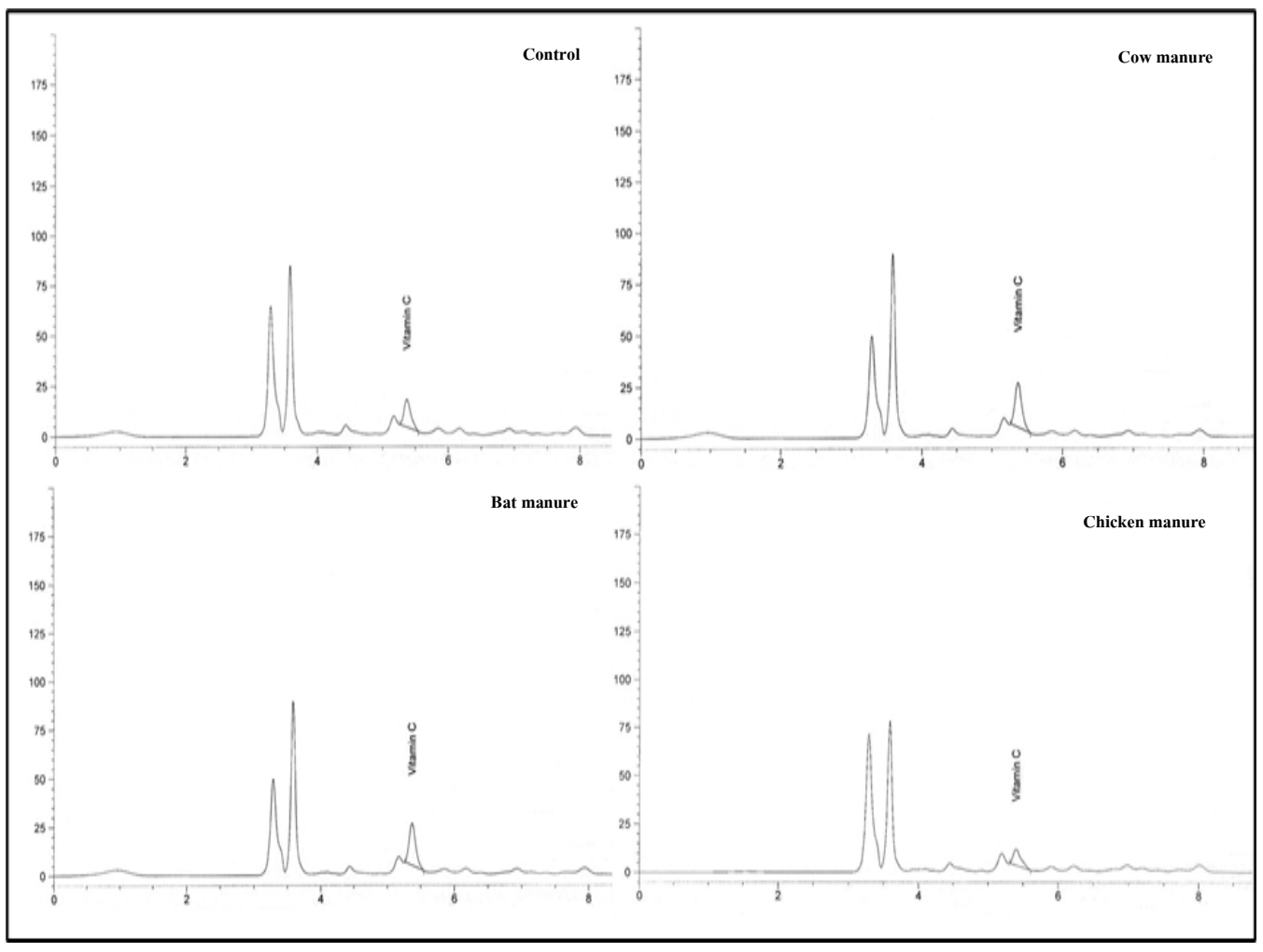

Figure 1. Vitamin $\mathrm{C}$ peak of Artemisia lactiflora at different organic fertilizer obtained by HPLC analysis.

Table 4 . Effect of different organic fertilizer on vitamin C, chlorophyll content and total phenolic compounds of Artemisia lactiflora.

\begin{tabular}{lccc}
\hline Organic fertilizers & $\begin{array}{c}\text { Vitamin C } \\
(\mathbf{m g} / \mathbf{1 0 0} \text { g FW) }\end{array}$ & $\begin{array}{c}\text { Chlorophyll } \\
\text { content (mg/g FW) }\end{array}$ & $\begin{array}{c}\text { Total phenolic } \\
\text { compounds } \\
(\mathbf{m g ~ G A E} / \mathbf{g ~ D W})\end{array}$ \\
\hline Control & $1.13 \pm 0.12^{\mathrm{ab}}$ & $0.24 \pm 0.03^{\mathrm{d}}$ & $4.35 \pm 0.18^{\mathrm{c}}$ \\
Cow manure & $1.35 \pm 0.02^{\mathrm{a}}$ & $0.43 \pm 0.09^{\mathrm{c}}$ & $4.84 \pm 0.06^{\mathrm{a}}$ \\
Chicken manure & $0.93 \pm 0.06^{\mathrm{c}}$ & $0.93 \pm 0.04^{\mathrm{a}}$ & $4.45 \pm 0.04^{\mathrm{bc}}$ \\
Bat manure & $1.24 \pm 0.04^{\mathrm{ab}}$ & $0.53 \pm 0.05^{\mathrm{b}}$ & $4.58 \pm 0.03^{\mathrm{bc}}$ \\
\hline
\end{tabular}

Note: Different letters within a column indicate significant differences at $P<0.05$.

\section{Total phenolic compounds}

The results of total phenolic compounds in this current study ranged from 4.35-4.84 mg GAE/g DW (Table 4). There showed the application of cow manure could lead to the superior results when compared with the other organic fertilizers. The results of this study showed significant differences $(P<0.05)$ for content of total phenolic compounds due to effect of different organic manures. The highest of total phenolic compounds were recorded in the cow manure 
application with values of $4.84 \pm 0.06 \mathrm{mg} \mathrm{GAE} / \mathrm{g} \mathrm{DW}$. In addition, the lowest of phenolic content was obtained in a control treatment with the value of $4.35 \pm 0.18$ mg GAE/g DW.

\section{DISCUSSION}

The highest of yield and the chlorophyll content in the Artemisia Lactiflora were obtained in a chicken manure compared with the other treatments. This can be attributed to the higher amounts of nitrogen in chicken manure (Table 1). The nitrogen $(\mathrm{N})$ has a main effect on a growth development, yield and plant quality. In addition, nitrogen atoms have been found in a biological molecule (e.g. porphyrins) which found in the chlorophyll pigments. Therefore, a crop yield and chlorophyll content were increased with the higher level of nitrogen. The result was similar to the report of Singh et al., (2016) that stated that the yield of the Zingiber officinale Rosc. was increased when increasing rates of nitrogen fertility. In addition, the higher of nitrogen could increase the chlorophyll content in the leaf samples, which was corresponded to the previous report (Hokamlipoir et al., 2011). This finding suggested that the chicken manure might has an impact on the production of chlorophyll pigment.

Vitamin $\mathrm{C}$ and total phenolic content were increased with com manure application. This result suggested that cow manure might has positive effect on vitamin $\mathrm{C}$ production and total phenolic content in these plants. According to the Table 1, cow manure showed the lowest content of nitrogen $(1.11 \%)$ and may be led to the nitrogen deficiency in these herbs. Boussadia et al., (2010) reported the nitrogen deficiency increases the level of starch and soluble sugars, which are the major molecules for the ascorbate biosynthesis in the D-mannose/L-galactose or Smirnoff-Wheeler pathway (Figure 2) (Akrma et al., 2017). Furthermore, Zhang et al., (2016) described that nitrogen deficiency in cucumber plants caused higher concentrations of ROS in their leaves, which ROS may cause oxidative damage to the plants. Therefore, the synthesis of vitamin $\mathrm{C}$ in plants could prevent the plant damages. Hence, this might be another reason to explain why the highest vitamin $\mathrm{C}$ was found in White mugwort with cow manure application.

Besides the impact on vitamin $\mathrm{C}$ content, cow manure also showed the benefit on the levels of total phenolic compounds in plant leaves. Our result was similar to some studies (Ibrahim et al., 2011; Ibrahim et al., 2013), which claimed that total phenolic compound could be decreased under fertilizers with high $\mathrm{N}$ content. This might be the reason that White mugwort showed highest total phenolic compound when obtained cow manure fertilizer. 


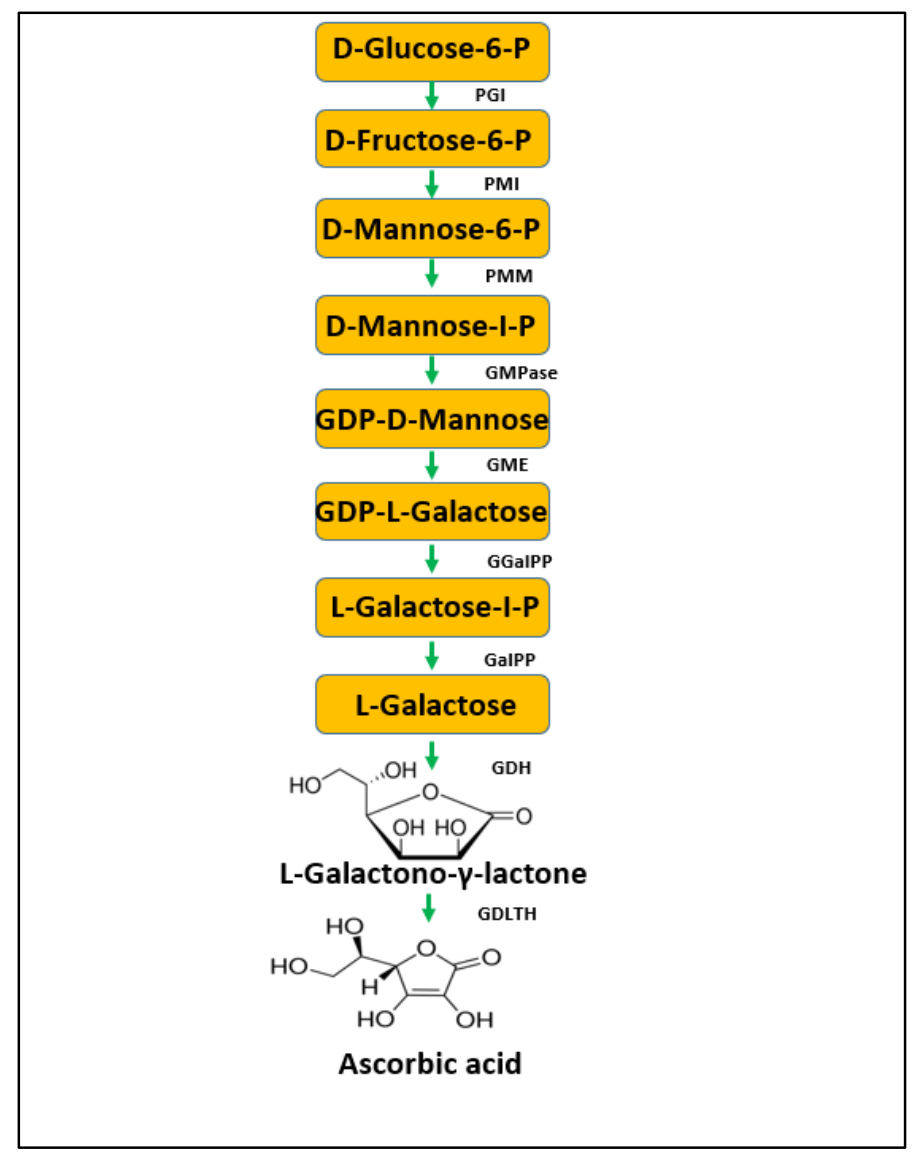

Figure 2. Smirnoff-Wheeler pathway for ascorbic acid biosynthesis in plants (Hemavathi et al., 2009). (PGI: phosphogluco isomerase, PMI: phosphomanno isomerase, PMM: phosphomanno mutase, GMPase: GDP-D-mannose pyrophosphorylase, GME: GDP-mannose3,5epimerase, GGalPP: GDP-L-galactose pyrophosphatase, GalPP: Lgalactose-1phosphate phosphatase, GDH: L-galactose dehydrogenase, GALDH: L-galactono1, 4-lactone dehydrogenase).

\section{CONCLUSION}

Artemisia lactiflora with chicken manure showed the best result in terms of highest levels of yield and chlorophyll content, whereas the highest contents of the vitamin $\mathrm{C}$ and total phenolic compounds were obtained from sampled plants with cow manure application. Therefore, according to all of the results shown above we believe that cow manure promotes of produced the secondary metabolites in white mugwort. In addition, Artemisia lactiflora also has potential for using as natural sources for antioxidants. 


\section{ACKNOWLEDGEMENTS}

The authors are grateful to the Department of Medicinal Plant Science, Faculty of Agricultural Production, Maejo University for a fully support on this research work.

\section{REFERENCES}

Akram, N.A., Shafiq, F., and Ashraf, M. 2017. Ascorbic acid a potential oxidant scavenger and its role in plant development and abiotic stress tolerance. Frontiers in Plant Science. 8: 613. https://doi.org/10.1080/01904167. 2012.636120

Almatar, M., Ekal, H., and Rahmat, Z. 2014. A glance on medical applications of orthosiphon stamineus and some of its oxidative compounds. International Journal of Pharmaceutical Sciences Review and Research, 24: 83-88.

Boussadia, O., Steppe, K., Zgallai, H., Hadj, S.B.E., Braham, M., Lemeur, R., and Labeke, M.C.V. 2010. Effects of nitrogen deficiency on leaf photosynthesis, carbohydrate status and biomass production in two olive cultivars 'meski' and 'koroneiki'. Scientia Horticulturae. 123(3): 336-342. https://doi.org/10.1016/j.scienta.2009.09.023

Fallah, S., Rostaeia, M., Lorigooinib, Z., and Surk, A.A. 2018. Chemical compositions of essential oil and antioxidant activity of dragonhead (Dracocephalum moldavica) in sole crop and dragonhead soybean (Glycine max) intercropping system under organic manure and chemical fertilizers. Industrial Crops and Products. 115: 158-165. https://doi.org/ 10.1016/j.indcrop.2018.02.003

Hafizah, A.H., Zaiton, Z., Zulkhairi, A., Ilham, A.M., Megat, N.M., and Zaleha, A.M. 2010. Piper sarmentosum as an antioxidant on oxidative stress in human umbilical vein endothelial cells induced by hydrogen peroxide. Journal of Zhejiang University. Science. B. 11(5): 357-365. http://doi.org/ 10.1631/jzus.B0900397

Hemavathi, Upadhyaya, C.P., Young, K.E., Akula, N., Kim, H.S., Heung, J.J., Oh, O.M., Aswath, C.R., Chun, S.C., Kim, D.H., et al. 2009. Overexpression of strawberry D-galacturonic acid reductase in potato leads to accumulation of vitamin $\mathrm{C}$ with enhanced abiotic stress tolerance. Plant Science. 177: 659-667.

Hokmalipour, S., and Darbandi, M.H. 2011. Effects of nitrogen fertilizer on chlorophyll content and other leaf indicate in three cultivars of maize (zea mays L.). World Applied Sciences Journal. 15(12): 1780-1785. 
Hunaefi, D., and Smetanska, I. 2013. The effect of tea fermentation on rosmarinic acid and antioxidant properties using selected in vitro sprout culture of Orthosiphon aristatus as a model study. Springerplus. 2(1): 2193-1801. http://doi.org/10.1186/2193-1801-2-167

Ibrahim, M., Jaafar, H., Karimi, E., and Ghasemzadeh, A. 2013. Impact of organic and inorganic fertilizers application on the phytochemical and antioxidant activity of Kacip Fatimah (Labisia pumila Benth). Molecules. 18(9): 10973-10988. http://www.mdpi.com/1420-3049/18/9/10973.

Ibrahim, M.H., Jaafar, H.Z.E., Rahmat, A., and Rahman, Z.A. 2011. Effects of nitrogen fertilization on synthesis of primary and secondary metabolites in three varieties of Kacip Fatimah (Labisia pumila Blume). International Journal of Molecular Sciences. 12(8): 5238-5254. http://www.mdpi.com/ 1422-0067/12/8/5238

Islam, M.A., Islam, S., Akter, A., Rahman, Md H., and Nandwani, D. 2017. Effect of organic and inorganic fertilizers on soil properties and the growth, yield and quality of tomato in Mymensingh, Bangladesh. Agriculture. 7(18): 37. https://doi.org/10.3390/agriculture703001

Kamble, P.N., Giri, S.P., Mane, R.S., and Tiwana, A. 2015. Estimation of Chlorophyll content in young and adult leaves of some selected plants. Universal Journal of Environmental Research and Technology. 5(6): 306-310.

Kulprachakarn, K., Pangjit, K., Paradee, N., Srichairatanakool, S., Rerkasem, K., and Ounjaijean, S. 2019. Antioxidant properties and cytotoxicity of White Mugwort (Artemisia lactiflora) leaf extract in human hepatocellular carcinoma cell line. Walailak Journal of Science and Technology. 16(3): 195-192.

Lesing, S. 2015. Effect of organic fertilizer on growth and yield quality of white mugwort organic farming management [Master's thesis]. [Bangkok]: Thammasat University.

Namjooyan, F., Azemi, M., and Rahmanian, V. 2010. Invertigation of antioxidant activity and total phenolic content of various fractions of aerial parts of Pimpinella barbata(Dc.) Boiss. Jundishapur. Journal of Natural Pharmaceutical Products. 5(1): 1-5.

Pandey, V., and Patra, D.D. 2015. Crop productivity, aroma profile and antioxidant activity in Pelargonium graveolens L Hér. under integrated supply of various organic and chemical fertilizers. Industrial Crops and Products. 67: 257-263. https://doi.org/10.1016/j.indcrop.2015.01.042

Park, S., Arasu, M.V., Lee, M.K., Chun, J.H., Seo, J.M., Lee, S.W., Al-Dhabi, N.A., and Kim, S.J. 2014. Quantification of glucosinolates, anthocyanins, free amino acids, and vitamin $\mathrm{C}$ in inbred lines of cabbage (Brassica oleracea L.). Food Chemistry. 145: 77-85. 
Pumtes, P., Kongbangkerd, T., Rojsunthornkitti, K., and Jiirepotch, N. 2012. Effect of extractions on antioxidation activites of some thai herbs. In: The $4^{\text {th }}$ Science Research Conference, 12-13 March 2012. Faculty of Science, Naresuan University. Thailand. p.52-54.

Rossetto, M.R.M., Shiga, T.M., Vianello, F., and Lima, G.P.P. 2013. Analysis of total glucosinolates and chromatographically purified benzyl glucosinolate in organic and conventional vegetables. LWT - Food Science and Technology. 50(1): 247-252. https://doi.org/10.1016/j.lwt.2012.05.022

Roussos, P.A., Gasparatosb, D., Kechrologoua, K., Katsenosc, P., and Bouchagierda, P. 2017. Impact of organic fertilization on soil properties, plant physiology and yield in two newly planted olive (Olea europaea L.) cultivars under Mediterranean conditions. Scientia Horticulturae. 220: 1119. https://doi.org/10.1016/j.scienta.2017.03.019

Roussos, P.A., Flessoura, I., Petropoulos, F., Massas, I., Tsafouros, A., Ntanos, E., and Denaxa, N.K. 2019. Soil physicochemical properties, tree nutrient status, physical, organoleptic and phytochemical characteristics and antioxidant capacity of clementine mandarin (Citrus clementine cv. SRA63) juice under integrated and organic farming. Scientia Horticulturae. 250: 414-420. https://doi.org/10.1016/j.scienta.2019.02.082

Saokaew, S., Suwankesawong, W., Permsuwan, U., and Chaiyakunapruk, N. 2011. Safety of herbal products in thailand an analysis of reports in the thai health product vigilance center database from 2000 to 2008. Drug Safety. 34(4): 339-350.

Siddiqui, Y., Islam, T.M., Naidu, Y., and Meon, S. 2011. The conjunctive use of compost tea and inorganic fertiliser on the growth, yield and terpenoid content of Centella asiatica (L.) urban. Scientia Horticulturae. 130(1): 289295. https://doi.org/10.1016/j.scienta.2011.05.043

Singh, M., Khan, M.M.A., and Naeem, M. 2016. Effect of nitrogen on growth, nutrient assimilation, essential oil content, yield and quality attributes in Zingiber officinale Rosc. Journal of the Saudi Society of Agricultural Sciences. 15: 171-178.

Testing Methods for Fertilizers. 2016. Incorporated Administrative Agency Food and Agricultural Materials Inspection Center. Japan.

Zhang, X., Yu, H.J., Zhang, X.M., Yang, X.Y., Zhao, W.C., Li, Q., and Jiang, W.J. 2016. Effect of nitrogen deficiency on ascorbic acid biosynthesis and recycling pathway in cucumber seedlings. Plant Physiology and Biochemistry. 108: 222-230. https://doi.org/10.1016/ j.plaphy.2016.07.012 


\section{Supplement}

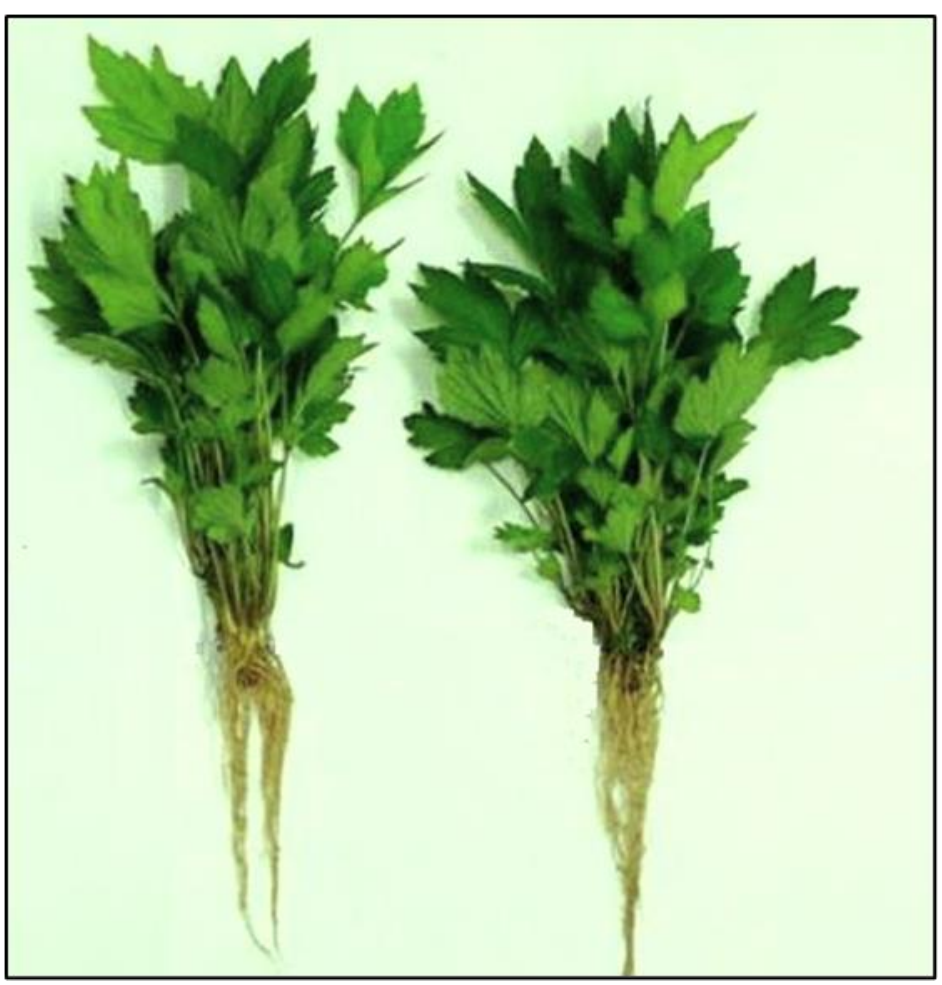

Figure S1. Artermisia lactiflora 